\title{
Reconciling intergenerational conflicts with imaginary future generations: evidence from a participatory deliberation practice in a municipality in Japan
}

\author{
Keishiro Hara ${ }^{1} \cdot$ Ritsuji Yoshioka $^{2} \cdot$ Masashi Kuroda $^{1} \cdot$ Shuji Kurimoto ${ }^{1} \cdot$ Tatsuyoshi Saijo $^{3,4}$
}

Received: 7 October 2017 / Accepted: 11 March 2019 / Published online: 22 March 2019

(c) The Author(s) 2019

\begin{abstract}
Coping with intergenerational conflicts is one of the fundamental keys to building a sustainable society. However, current decision-making systems tend to be inclined towards the preferences of present generations, simply because future generations do not yet exist and therefore cannot participate in present-day negotiating processes. In this paper, with an aim towards reconciling possible intergenerational conflicts, we present the first attempt at creating a participatory intergenerational deliberation practice by creating "imaginary future generation" groups to represent future generations and negotiate with present-generation groups regarding future visions and associated decision making. To accomplish this, a series of workshops were organized in a local municipality in Japan in which participating imaginary future-generation groups and present-generation groups first deliberated separately, and then worked together, to form a consensus over prioritizing policy measures associated with their separate visions of the municipality in 2060. We then analyzed deliberation and consensusbuilding processes used and observed a stark contrast in deliberation styles and priorities between the groups. For example, imaginary future-generation-group measures were primarily characterized by utilizing existing local resources, while the present-generation groups aimed more at solving current problems. Notably, the consensus-building processes resulted in choosing more than half of the measures originally proposed by the imaginary future-generation groups, thereby indicating that decision-making preferences had shifted to future generations. We contend that our approach, which is based on introducing imaginary future-generation groups as stakeholders, could provide indicators towards coping with intergenerational conflicts via present-day decision-making processes.
\end{abstract}

Keywords Future design · Participatory deliberation · Imaginary future generations · Intergenerational conflicts · Consensus building

Handled by: Osamu Saito, United Nations University Institute for the Advanced Study of Sustainability, Japan.

\section{Keishiro Hara}

hara@ceids.osaka-u.ac.jp

1 Graduate School of Engineering, Osaka University, Suita, Japan

2 Yahaba Town, Iwate Prefecture, Japan

3 Research Institute for Future Design, Kochi University of Technology, Kochi, Japan

4 Research Institute for Humanity and Nature, Kyoto, Japan

\section{Introduction}

In recent decades, a variety of complex problems, ranging from climate change to ecosystem degradation, have emerged and are now posing serious threats to the sustainability of our societies. To cope with these challenges, "sustainability science" has been playing essential roles. In particular, it has explored the following aspects: (1) comprehensively grasping and understanding the structure and cause-and-effect relationships of various problems; (2) proposing visions of sustainable societies, and then describing and designing future scenarios to fulfill those visions; (3) integrating and formulating knowledge for fulfilling the created visions; (4) creating multidimensional assessments of sustainable socioeconomic and technology systems; and (5) implementing strategic management and measures to effect 
social transformation and transition towards the realization of those visions (Kates et al. 2001; Clark and Dickson 2003; Komiyama and Takeuchi 2006; Kumazawa et al. 2014).

While theoretical research and practices relevant to the abovementioned domains have been extensively carried out in pursuit of sustainability societies, one fundamental challenge still remains, that is, how to reconcile the conflicts and tradeoffs between the present generation and future unborn generations. Here, we must begin by acknowledging that any decision-making processes or practices used by present generations will directly or indirectly influence future generations. This is clearly illustrated by various sustainability problems, such as climate change and resource depletion. The fundamental problem, however, is that the future generations cannot make their voice heard in any present-day decision-making and negotiation processes simply because they do not yet exist.

Although the notion of sustainable development defined by the World Commission on Environment and Development (1987), which reads in part, "Sustainable development is development that meets the needs of the present without compromising the ability of future generations to meet their own needs." is globally accepted, the concept has not been operationalized in reality. The heart of these problems is an intergenerational tradeoff between current and future generations in relation to convenience and responsibility. In other words, a serious conflict of interest exists, and the fact that none of the stakeholders on one side of this conflict of interest, specifically, future generations, are available to negotiate this tradeoff is decisively important.

As argued above, it is important that any sustainable development effort to reshape society considers the viewpoints and interests of future generations. Yet, in practice, explicitly reflecting the interests of a future society, and then making decisions that reconcile intergenerational conflicts of interest and other conflicts, is not an easy matter. Indeed, making concessions for the benefit of future generations instead of pursuing the needs of the present generation is fundamentally quite difficult, given that any decision making and planning by present-day individuals will be biased to the present situation, and since it is difficult for one generation to care about subsequent generations (Saijo 2018; Sherstyuk et al. 2016). While both self-regarding preferences and other-regarding preferences are part of human nature and although encouraging collective action is essential for the well-being of future generations (Fischbacher et al. 2001; Fehr-Duda and Fehr 2016), it would be unrealistic to expect individuals of our present generation to consistently make decisions that might benefit future generations at the expense of their own generation (Saijo 2019).

In addition to the factors associated with such aspects of human nature, under the societal systems in modern society, such as the market, it is unlikely that the conflict between current and future generations can be eliminated to enable transformation to a sustainable society. The market that underpins our society exerts a powerful influence on the distribution of resources to satisfy the needs of the present generation, and it cannot consider the needs of future generations.

Meanwhile, in terms of future visioning and scenario making, numerous efforts have been made and put into practice in the field of sustainability science. In particular, participatory methods have been applied to envisioning sustainable futures and sustainability backcasting scenarios to incorporate personal preferences and reflect normative aspects (Kishita et al. 2016; Schneider and Rist 2014; Carlsson-Kanyama et al. 2008; Quist and Vergragt 2006). In addition, Wiek and Iwaniec (2014) reviewed relevant visioning studies and synthesized the quality criteria needed to inform a methodology for visioning sustainability. Such participatory methods have also been used for consensus building and policy debates in various fields such as urban planning (Hara et al. 2016a, b; Innes and Booher 2003), and a variety of methods using creative activities, including role-playing, have been developed and applied to expand the capacity of people to envision futures and to detail future policy options via participatory approaches (Iacovidou and Wehrmeyer 2014; Ligtvoet et al. 2016; Eickhoff and Geffer 2009). While these methods might help to tackle future uncertainties, when pursuing sustainability, it is also essential to explore approaches that take into account the preferences of future generations in a more explicit fashion.

Therefore, we can see that building a sustainable society that is truly and uninterruptedly connected to future generations requires a methodology and mechanism that facilitates a form of decision making which is capable of counteracting human short-sightedness (Sapolsky 2012). To cope with the fundamental challenge of incorporating the preferences of future generations in present decision making and vision setting, a new institutional mechanism, whereby "imaginary future generation" groups tasked with representing and speaking for the benefit of the future generation negotiate with present-generation groups in an effort to reconcile intergenerational conflicts and make better decisions by balancing the benefits of both present and future generations, has been proposed (Hara 2016; Hara and Saijo 2017; Hara et al. 2015; Saijo 2019; Kamijo et al. 2017). Under this concept, decision making and vision design are achieved by negotiation and consensus building between the present and imaginary future generations. While other attempts to allow people to experience envisioned futures have been carried out (Oliver 2008; Kuzmanovic and Gaffney 2017), there has yet to be a study in which an imaginary future generation is created as a stakeholder that can take part in decisionmaking processes to reconcile intergenerational conflicts and thus achieve sustainability. 
Relevant studies have been carried out to examine the effectiveness and roles involved in the creation of imaginary future generations, particularly from the viewpoint of overcoming present-day short-sightedness. For example, Kamijo et al. (2017) examined how the presence of negotiators for a future generation can increase the benefits inherited by future generation through a laboratory-controlled intergenerational sustainability dilemma game (ISDG).

While previous studies such as the above suggest the effectiveness of creating imaginary future generations to cope with intergenerational conflicts, no study has previously been performed that involved participatory deliberation in the real world by introducing the concept of imaginary future generations. In this paper, we present the first such participatory deliberation practice by creating imaginary future-generation groups that aim for vision setting and relevant decision making in a local town in Japan, and present implications derived from the resulting deliberations and consensus building between the imaginary future- and present-generation groups. In particular, we present how priorities and decisions made by both present- and imaginary future-generation groups were altered after negotiations and consensus-building processes. We also summarize the pattern of judgements and the characteristics of deliberation employed by each group and present the stark contrast in the deliberation characteristics shown by the imaginary future- and present-generation groups. Furthermore, we demonstrate that the ideas proposed by imaginary futuregeneration groups could influence the decision making of present-generation groups, and that consensus-building processes by the pair groups resulted in choosing more than half of the ideas originally proposed by the imaginary futuregeneration groups. With these points in mind, we argue that our approach has the potential to yield a decision-making process that could overcome human short-sightedness and take into account the possible values and benefits of future generations, thereby paving a way to cope with intergenerational conflicts.

The remainder of this paper is organized as follows. "Creating imaginary future generations: incorporating the viewpoints of future generations into the present" section demonstrates the significance of incorporating the preference of future generations in present society to cope with the intergenerational conflicts in decision making. Furthermore, we introduce our approach to creating imaginary futuregeneration groups as "stakeholders" who can participate in decision making and negotiating processes with the present generation, along with implications from previous studies that applied the approach of creating imaginary future generations. "Case study: Participatory deliberation with imaginary future generations" section presents the methods and processes of our case study involving citizen participation in Yahaba Town, Iwate Prefecture, which is located in the northern part of Japan, during which both present- and imaginary future-generation groups deliberated for vision setting and identifying policy measures aimed at supporting the envisioned future, and then negotiated together to develop a consensus over the most essential policy measures. "Results" section discusses the results from our case study, highlighting how priorities and decision making by each group changed through the deliberations held within each group, and the negotiation processes between imaginary future-generation and present-generation groups. "Discussion" section summarizes our future research agenda, and is followed by our conclusions.

\section{Creating imaginary future generations: incorporating the viewpoints of future generations into the present}

Given the reality that short-sightedness is a part of human nature, as well as social systems such as markets (as discussed in the Introduction), it is clear that any kind of decision making which sufficiently takes future generations into account is going to be difficult to achieve. Nevertheless, some recent studies have already started to look at transforming our social systems so that the interests of future generations can somehow be taken into account in the present day. For example, Demeny (1986) focused on voting age, proposing a system in which people of all ages have the right to vote (i.e., Demeny voting); for all those under a certain age, a parent casts a vote by proxy. However, there are virtually no real-world examples of this kind of system in operation, and relevant studies to date are limited to dealing with experiments in laboratory settings (Kamijo et al. 2015).

In light of this awareness, the authors and associated researchers have undertaken research on a new kind of theoretical and practical science for designing a future society, and are making it a reality through a form of decision making that attempts to reflect the viewpoints and interests of future generations in the present in a more explicit manner, thus overcoming short-sightedness of human beings and the characteristics of current social systems, as discussed earlier (Hara 2016; Hara and Saijo 2017; Hara et al. 2015; Saijo 2019; Kamijo et al. 2017; Shahrier et al. 2017; Nakagawa et al. 2019). The relevant research has aimed at constructing a methodology for future-oriented vision creation and decision making that incorporates the viewpoints and preference of future generations. One promising approach that we have proposed is to create imaginary future generations by assigning stakeholders in the decision-making process with the responsibility of advocating the interests of future generations. The imaginary future-generation advocates then negotiate and (hopefully) reach consensus with representatives of the 
present generation, thereby overcoming intergenerational conflicts of interests and appropriately coordinating shared interests. This method makes it possible to create decisions that reflect the interests of future generations to a certain degree, which we call "future design." In addition, there are some academic backgrounds that have become firmly established in recent years behind our ideas of creating imaginary future generations. These employ the use of empirical methods in the social sciences, the elucidation of social behavior in neuroscience, and theories of justice in philosophy (Saijo 2017). We hypothesize that a person exhibits "futurability" when this person experiences an increase in happiness as a result of deciding and acting to forego current benefits as long as it enriches future generations. Future design is, thus, the praxis of creating futurability through designing social systems (Saijo 2019).

A variety of approaches have been taken to examine the function and effectiveness of imaginary future generations, particularly from the viewpoint of overcoming shortsightedness. For example, in one experiment, groups that included an imaginary future generation demonstrated the capacity to make judgments and decisions that opted to leave resources for future generations, even if that meant reducing the remuneration which the group itself would take home (Kamijo et al. 2017). It has also been demonstrated that the decisions of test subjects that were asked to rank multiple policy issues in order of importance in online questionnaire surveys differed significantly depending on whether they were assigned the role of representing the interests of future generations or simply asked to answer without constraints (Hara et al. 2015). For example, when asked to respond from the standpoint of the present generation-without any imposed conditions - people tended to give the highest priority to the urgent and important policy issues facing the present generation, such as "economic development" and the "wealth gap." In contrast, when they were asked to rank issues as advocates for the interests of future generations, they tended to give higher priority to policy issues that take longer to resolve, such as "global environmental problems."

All the above imply that if people are clearly assigned the role of representing the interests of future generations, their priorities tend to change, and they become capable of overcoming their own short-sightedness and making decisions that positively consider the interests of future generations. These observations arguably support our hypothesis regarding the activation of "futurability." Associated experiments and studies are being implemented under various conditions to delve further into the mechanisms behind the behaviors and decision making of imaginary future generations. In the meantime, it is urgently necessary to demonstrate how the concept of an imaginary future generation will work out in real-world participatory deliberations and decision making, as will be discussed below.

\section{Case study: participatory deliberation with imaginary future generations}

\section{Case study area}

In our case study, we carried out future design deliberations with the participation of local citizens in Yahaba Town in Iwate Prefecture, which is a dormitory town located just south of Morioka City, the prefectural capital. About $11 \%$ of Yahaba Town's economic output is derived from primary industry, while the secondary and tertiary industries account for $18 \%$ and $71 \%$, respectively. Its population is approximately 27,000 , but the city is not facing a declining population, in part because the Iwate Medical University, which is located there, attracts numerous students and workers.

Since 2008, Yahaba Town has been well known for its efforts to implement participatory workshops in which local citizens are invited to discuss and participate in the creation of a waterworks visions for the town. Since the expenditure associated with waterworks basically consists mostly of fixed costs, it is generally assumed that, under financial constraints of local municipalities, the scheduling of pipe replacement work is figured in hundred-year units. Indeed, there are specific rules set forth by an external agency of the Ministry of Land, Infrastructure, Transport and Tourism of Japan regarding when and which pipes are to be replaced in particular areas.

Meanwhile, in Yahaba Town, in addition to the physical rules assigned by the government, the citizens themselves have created new social rules and evaluation criteria aimed at, for example, accelerating the replacement of waterworks infrastructure based on such important points in the town as hospitals and evacuation sites. Comparing these new rules to the government-mandated rules, they successfully designed a town vision for piping replacement up to the year 2030. Our research group selected the town as a case study area because of its long experience with, and capabilities for, participatory deliberation and consensus building that involves inviting local citizens to participate in vision setting.

\section{Workshop methods and conditions}

The future design workshop, which was held in close collaboration between university researchers (including the authors) and Yahaba Town Hall personnel in fiscal year 2015 (FY2015) based on the guidelines below, centered on community participation-style deliberations held with the goal of creating a future vision of the town in 2060. Yahaba Town had been working in preparation for the 
creation of an official document that will address a Japanese government policy aimed at overcoming population declines and revitalizing local economies. Thus, all of the visions and measures identified throughout the workshop were crafted for inclusion in the policy document prepared by the town. Hence, each participant was to take into account the issues, such as population and revitalizing the town economy, when proposing sustainable and desirable visions, as well as their associated policy measures.

These Yahaba Town future design workshops were held on a total of five occasions in FY2015 (August 27, 2015; September 29, 2015; November 19, 2015; January 12, 2016; and February 2, 2016). Each workshop session lasted $2.5 \mathrm{~h}$. The overall scheme of the deliberation processes, including consensus building in FY2015, is shown in Fig. 1. A group of approximately 20 people, the composition of which remained basically unchanged throughout the five occasions, participated in the deliberations. The group consisted of men and women ranging in age from 20 to 80 . Yahaba town officials asked those who had participated in the waterworks and vision creation workshop described above to participate in the future design workshop and also solicited participation from citizens by announcing the workshop on the town's webpage. Ultimately, after taking into consideration the balance in terms of ages and gender, about 20 participants were selected. Notably, those who had previously experienced participation in such deliberations were very active in raising ideas and proposals throughout the workshop, and the inclusion of those experienced participants did not result in any specific negative effects, because the deliberation theme was completely different from their previous discussions (i.e., waterworks vision).

Except for the first workshop, during which an evaluation of past trends was the main theme of deliberation, the citizen participants were divided into four groups, each comprising about five people in a balanced mix of genders and ages. Two of the groups (A and B) were categorized as imaginary future-generation groups, and the two others groups $(\mathrm{C}$ and $\mathrm{D})$ were assigned to represent the present generation. Apart from the fifth (and final) workshop aimed at consensus building between present and future generations, each group engaged in deliberations in a separate room, so that no group would learn from or be influenced by what the other groups discussed.

As a snapshot of these workshops, the following details of the third future design workshop held at Yahaba Town Hall on November 19, 2015 (the third workshop) are provided. This workshop, which aimed at developing a vision for 2060, involved 20 participants (6 men and 14 women), as well as 8 facilitators (5 Yahaba Town Hall staff members and 3 university faculty members). The 20 participants were divided into four groups: A ( 2 men and 3 women, mean age
Fig. 1 Scheme of deliberation processes (FY 2015)

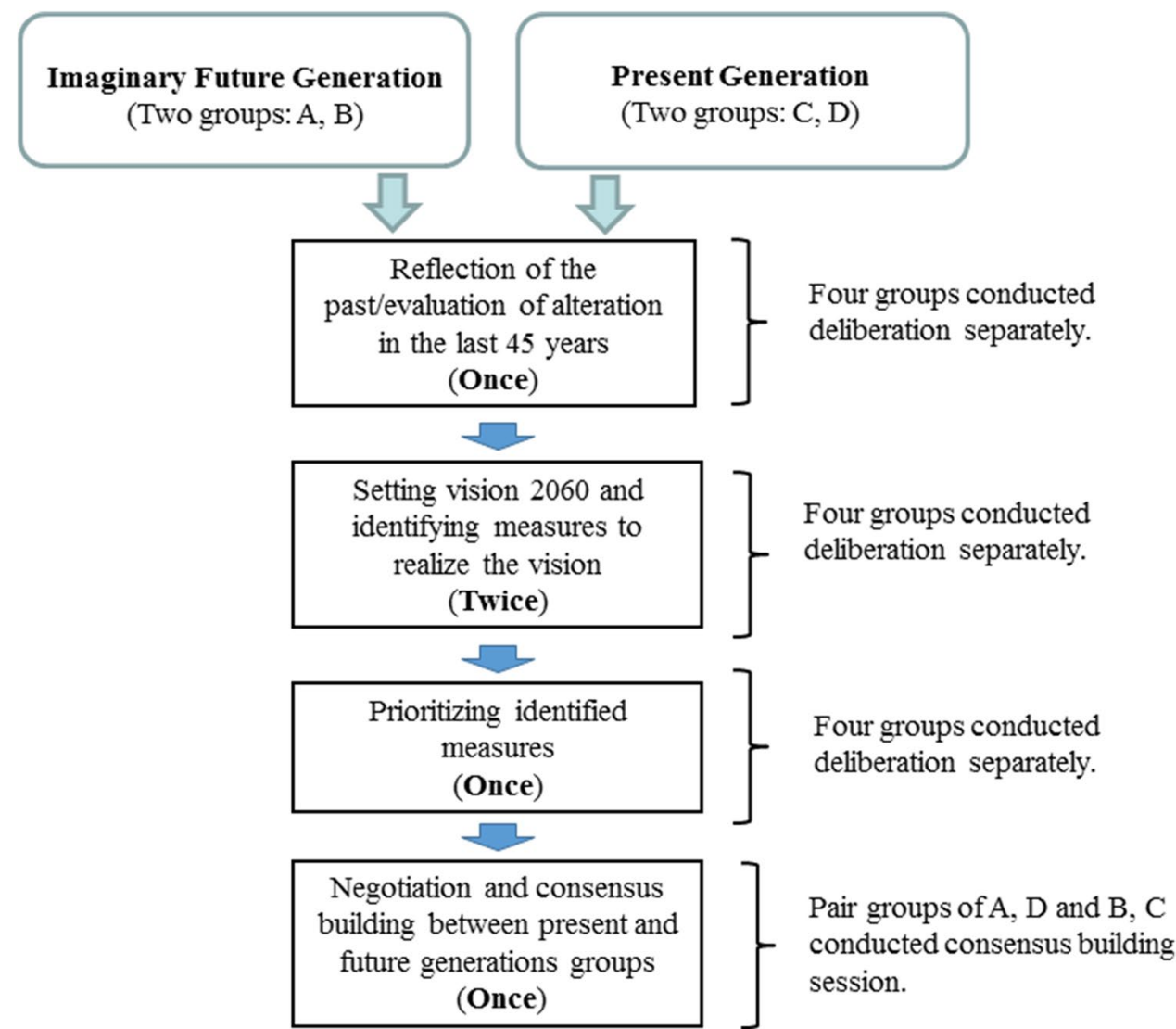


52), B ( 1 man and 4 women, mean age 51), C (2 men and 3 women, mean age 55), and D (1 man and 4 women, mean age 55). Note that there were relatively few younger participants, such as people (including students) in their twenties, primarily due to the fact that the deliberations were held on days when they were unavailable due to school or work.

During these sessions, all four groups debated the same issues, with the final goal of formulating "A Vision of Yahaba Town in 2060 and measures to realize the vision." Most importantly, the members of imaginary future-generation groups A and B were given additional instructions in each room before the deliberation began. They were tasked to address issues and visions from the standpoint of the people of 2060, and to represent the interests of that generation by assuming the role of people living at that time. Furthermore, they were clearly directed to consider, not the interests of themselves and their families, but those of their future generation and the whole of society. As supplementary information aimed at increasing their understanding, the researchers also explained the significance and meaning of representing future generations by providing some specific examples of long-timeframe issues, such as climate change. Note that, as a condition for becoming a future person of 2060 (imaginary future generation), the participants were asked to assume that they had time-traveled to the year 2060 without aging (i.e., they were of the same age in 2060 as at the present). The members of the imaginary future-generation groups wore special Yahaba Town happi coats to help them identify as part of the imaginary future generations. These instructions to future-generation-group members were repeated before each workshop, from the second to fifth events, before the start of deliberations.

To enhance the smoothness and effectiveness of the debate by visualizing participants' opinions, one Town Hall staff member was appointed to serve as a facilitator for each group, as well as a person to write down and illustrate the viewpoints of citizens on large sheets of paper (see Fig. 2).

\section{Details of deliberation and consensus-building processes}

The first workshop on the August 27, 2015 was dedicated to the evaluation of the transformations that had occurred within the town from the past to the present from multiple perspectives. Since the 2060 vision design covers a period of 45 years, the participants assessed the changes that the town had undergone over the previous 45 years, 1970-2015. To implement concrete discussions, the participating citizens were provided with various reference materials, such as town reports issued in 1970, aerial photographs, and urban development plans from 45 years ago. From the viewpoint of infrastructure development, lifestyle, and environment, the participants exchanged opinions about the transformation experienced by the town's residents in the past 45 years. The outcomes of the first workshop were used as references during the second and third workshops when they crafted proposals for a vision of Yahaba Town in 2060, along with the policies to support them.

From the second workshop onwards, the participants were divided into future-generation groups (A, B) and present-generation groups (C, D) and conducted deliberations individually in separate rooms. The second and third workshops were dedicated to identifying the concept and visions of Yahaba Town 2060, along with policy measures to achieve the visions from the broad viewpoints. In particular, each team member selected measures that should be implemented within five years to realize those visions. It should be noted that participants were also provided with basic statistics regarding the town, such as economic conditions and a population breakdown, as well as official predictions towards
Fig. 2 A scene at consensus building process between the present and future generations (the fifth workshop)

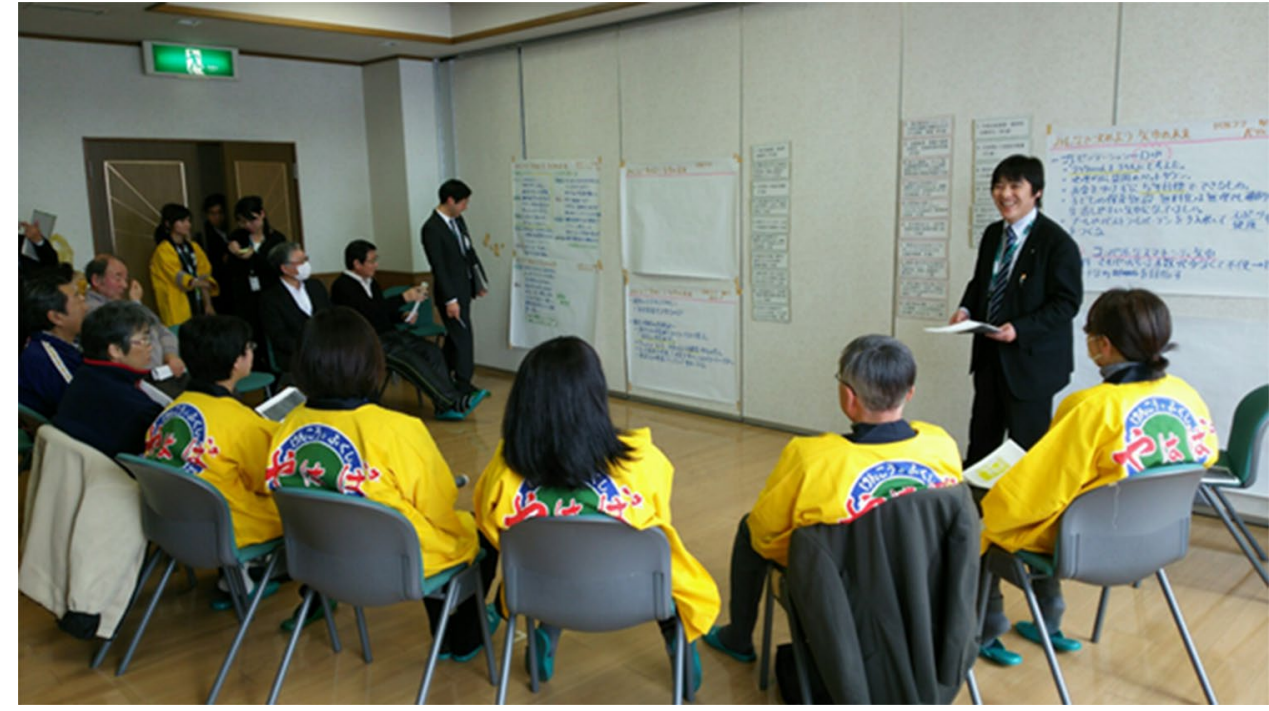


2020, which had been previously prepared by the city hall, for use as the basis for discussion.

During the fourth workshop, each group prioritized the most essential measures needed to achieve their 2060 vision. The session was carried out as follows. In advance of the workshop, researchers engaged with the series of workshops, including the authors, selected and prepared a list of the 24 most essential measures for inclusion under the categories of "urban planning" "facility development/ maintenance" "countermeasures for aging population" "invitation of enterprises" "agriculture" "tourism" "environmental management/measures for low-carbon society" "transportation" "health" and "others" based on the measures proposal worked out by each group during the second and third workshops (Table 1). Note that in preparing the 24 policy measures, the researchers selected 12 measures that had been proposed by Groups $\mathrm{C}$ and $\mathrm{D}$, and 12 measures proposed by Groups A and B. In other words, the researchers chose 12 sets that paired two similar but different concepts from the present- and imaginary future-generation groups.

Table 1 List of 24 measures selected from the second and third workshops (shared with each group for prioritization during the fourth workshop)

\begin{tabular}{|c|c|c|}
\hline Category & Item number & Details of policy measure \\
\hline \multirow[t]{2}{*}{ Town planning } & 1 & Establish parks that are relaxing, even if they do not offer special amenities \\
\hline & 2 & Establish large parks where children can play \\
\hline \multirow[t]{2}{*}{ Facility development/maintenance } & 3 & $\begin{array}{l}\text { Rather than relying on new construction such as playground equipment, take active steps } \\
\text { to leverage existing resources by reusing and repairing existing equipment }\end{array}$ \\
\hline & 4 & Establish childcare facilities \\
\hline \multirow[t]{4}{*}{ Countermeasures for aging population } & 5 & $\begin{array}{l}\text { Implement steps to realize a town that understands the needs of working women and } \\
\text { embraces diverse lifestyles, and that accepts the perspective of "house-husbands" }\end{array}$ \\
\hline & 6 & $\begin{array}{l}\text { Establish town planning processes that offer a better environment for raising children, } \\
\text { including the introduction of frameworks to send children to and pick them up from } \\
\text { school during winter }\end{array}$ \\
\hline & 7 & Provide free medical care or charge lower fees for children \\
\hline & 8 & Take proactive measures to offer matchmaking for those seeking marriage \\
\hline \multirow[t]{2}{*}{ Invitation of enterprises/industries } & 9 & $\begin{array}{l}\text { Promote sixth-sector industrialization of farming and attract businesses to realize } \\
\text { "Yahaba, a Healthy Town," where senior citizens can thrive }\end{array}$ \\
\hline & 10 & $\begin{array}{l}\text { Take active steps to attract businesses in order to secure opportunities for the present } \\
\text { generation of workers }\end{array}$ \\
\hline \multirow[t]{2}{*}{ Agriculture } & 11 & $\begin{array}{l}\text { Promote sixth-sector industrialization of farming, including branding (accompanied by } \\
\text { the introduction of the private sector) and a shift from quantity to quality }\end{array}$ \\
\hline & 12 & $\begin{array}{l}\text { Preserve the rural scenery/landscape of farming communities and promote local produc- } \\
\text { tion for local consumption }\end{array}$ \\
\hline \multirow[t]{2}{*}{ Tourism } & 13 & Develop tourism resources unique to Yahaba Town, such as the theme of Kenji Miyazawa \\
\hline & 14 & Make the local transportation system easier to use and develop promotional bus tours \\
\hline \multirow[t]{2}{*}{$\begin{array}{l}\text { Environmental management/measures } \\
\text { for low-carbon society }\end{array}$} & 15 & $\begin{array}{l}\text { Promote self-sufficiency in energy and local production for local consumption by convert- } \\
\text { ing waste into energy through technological innovation, for example }\end{array}$ \\
\hline & 16 & $\begin{array}{l}\text { Promote recycling and the collection of recyclable resources in each area and set up } \\
\text { designated boxes for sorting waste }\end{array}$ \\
\hline \multirow[t]{2}{*}{ Transportation } & 17 & $\begin{array}{l}\text { Propose and create Yahaba Town's concept of a transportation network inspired by } \\
\text { Galactic Railroad }\end{array}$ \\
\hline & 18 & $\begin{array}{l}\text { Promote the use of a sightseeing bus by revising existing bus routes and making the } \\
\text { names of bus stops easier to understand and remember }\end{array}$ \\
\hline \multirow[t]{2}{*}{ Health } & 19 & $\begin{array}{l}\text { Collaborate with the Iwate Medical University to actively promote health management } \\
\text { that leverages Wi-Fi and other information technologies, such as robotics, to control } \\
\text { data remotely }\end{array}$ \\
\hline & 20 & Secure a bus route to the Iwate Medical University \\
\hline \multirow[t]{4}{*}{ Others } & 21 & $\begin{array}{l}\text { Promote local unique businesses that contribute to town planning with a focus on well- } \\
\text { ness }\end{array}$ \\
\hline & 22 & Host festivals for all town citizens (this may become a tradition in the future) \\
\hline & 23 & Provide equal services across town \\
\hline & 24 & $\begin{array}{l}\text { Create karuta (traditional card puzzles) to facilitate the learning of place names that are } \\
\text { hard to pronounce and locate }\end{array}$ \\
\hline
\end{tabular}


At the beginning of the workshop, each group was provided with a copy of a list of 24 policies and asked to rank them. Note that, at this point, participants were not informed of how the list of 24 measures was chosen under what principles. The workshop instructors asked the groups to study the list, and then select and rank the 10 most important policy measures in terms of which should be implemented most urgently within five years. Specifically, each group was given a total of 100 points to allocate to their 10 selected policy measures, which were then ranked in order from the highest to the lowest score. The method and strategy for using their available points were left to the discretion of each group.

During the fifth (last) workshop, the groups were paired off, Group A with Group D and Group B with Group C (Fig. 2), where they faced each other for the first time to conduct negotiations and consensus building between the present and imaginary future generations. The aim of the fifth workshop was to allow each pair of groups to bring together their ranked lists of 10 policy measures from the fourth workshop, and then work together to produce a final shared 10 policy measures in order of importance, through an intergenerational process of negotiation and consensus building.

At the beginning, each group explained to the other in their group pair, their reasons for selecting and ranking their own list of measures and contents produced during the fourth workshop. The groups then temporarily separated to reconsider their policy measure selections and ranking to create a second proposal list of measures. At this point, the groups came together once again to form pairs (A with $\mathrm{D}$ and $\mathrm{B}$ with $\mathrm{C})$. After each of the groups had presented their second list, the two groups worked collectively to select and rank the final top 10 policy measures as a pair group. This fifth workshop was an attempt to recreate a process of overcoming intergenerational conflict by building a consensus between a present-generation group and an imaginary future-generation group.

For all sessions (first-fifth), the deliberations of all the groups were recorded to facilitate subsequent analysis of the debate content and thinking tendencies of each group.

\section{Results}

\section{Judgement trends and priorities by group}

Table 1 lists the 24 measures presented to each group for prioritization in the fourth workshop. Table 2 presents the 10 most important measures selected by each group at the end of the workshop. The number within each column indicates the item number of the policy measures listed in Table 1. Numbers within the parenthesis show the points allocated to each measure (100 points in total). An asterisk indicates
Table 2 Results of priority setting and raking of policy measures by each group

\begin{tabular}{lcrrr}
\hline Ranking & Group A & Group B & Group C & Group D \\
\hline 1 & $17^{*}(30$ points $)$ & $11^{*}(20)$ & $11^{*}(17)$ & $7(30)$ \\
2 & $12(20$ points $)$ & $16(15)$ & $7(15)$ & $3 *(15)$ \\
3 & $9 *(15$ points $)$ & $12(15)$ & $9 *(14)$ & $4(12)$ \\
4 & $19^{*}(15$ points $)$ & $13 *(15)$ & $13 *(11)$ & $5^{*}(10)$ \\
5 & $15^{*}(10$ points $)$ & $10(10)$ & $3 *(10)$ & $8(8)$ \\
6 & $13^{*}(5$ points $)$ & $7(10)$ & $23(10)$ & $9 *(9)$ \\
7 & $1 *(2$ points $)$ & $22 *(5)$ & $19 *(7)$ & $10(5)$ \\
8 & $3^{*}(1$ point $)$ & $23(5)$ & $14(6)$ & $11^{*}(5)$ \\
9 & $5^{*}(1$ point $)$ & $3^{*}(3)$ & $1 *(6)$ & $13 *(5)$ \\
10 & $22^{*}(1$ point $)$ & $9 *(2)$ & $15^{*}(4)$ & $16(5)$ \\
\hline
\end{tabular}

The number within each column indicates the item number of the policy measure listed in Table 1

The numbers of points indicated in parentheses are those allocated to the different measures (the points sum to 100)

An asterisk indicates that the associated policy measure was originally proposed by an imaginary future generation group (either A or B). This rule applies to Tables 3 and 4, as well

that the associated policy measure was originally proposed in the second and third workshops by an imaginary futuregeneration group (either A or B).

Some very important implications were obtained from the fourth workshop for ranking policy measures, and from the fifth workshop for consensus building. For example, it appears that the ranking sessions in the fourth workshop made the present-generation groups more aware of, and sympathetic to, the thinking of the future generation. Indeed, more than half of the final 10 policy measures selected in the ranking exercise by both present-generation groups corresponded to policies that were originally proposed by the imaginary future-generation groups in the second and third workshops (see Table 2). Examples include the future-generation proposals to promote "sixth sector industrialization of agriculture for primary producers' diversification into processing and distribution" and to "utilize Mt. Nansho, which is considered as the point of departure in the novel 'Night on the Galactic Railroad' by Miyazawa Kenji, as a local resource."

These ideas were completely absent from the ideas produced by the present-generation groups in their vision design workshops. In fact, there was a stark contrast in the ways of thinking of the visioning sessions (i.e., second and third sessions) by the present- and future-generation groups, as will be explained in "Characteristics of deliberation by group" section. We argue that, by having their attention drawn to them, people could become aware of, and appreciate the importance of, policies and ideas that they had not considered at all in normal vision design debates conducted from the standpoint of present generations. This finding, along 
with the fact that there was a stark contrast in ways of thinking by present and future generations, has implication to our hypothesis that under the existing participatory vision setting and future scenario making practices which have been carried out so far, futures are primarily created based on the perspectives of present generations who envision the future from their standpoints in present society (Hara et al. 2016a, b; Kishita et al. 2016).

In the fifth consensus-building session, the group pairs (A and D) and (B and C) came together to negotiate and build a consensus. Although each of the groups explained its ranked policy measures, the reasons for their policy selections, and the ranking decisions that it had made in the fourth session, the explanations of partner groups did not convince any of the groups to make changes when they subsequently formulated their second proposal. In other words, the intergenerational conflicts of interest had come to the surface by this point, whereas before negotiation each group's way of thinking seemed to be unanimous. Later, after each group came back with its second (unchanged) proposal, each of the group pairs began negotiating together towards a consensus by deciding on a final proposal and ranking the policies as a pair. Tables 3 and 4 summarize the results of consensus building, i.e., rankings before and after consensus building between Group A (imaginary future generation) and Group D (present generation), and between Group B (imaginary future generation) and Group C (present generation), respectively.

It appears that the consensus-building session created opportunities for mutual understanding with both groups. For example, the present-generation groups' high ranking of "provide free medical and daycare for children" was initially strongly opposed by the future-generation groups. Indeed,

Table 3 Ranking before and after negotiation and consensus building between Group A (imaginary future generation) and Group D (present generation)

\begin{tabular}{lccl}
\hline Ranking & Group A & Group D & Final result \\
\hline 1 & $17^{*}$ & 7 & $12^{\mathrm{A}}$ \\
2 & 12 & $3 *$ & $15^{* \mathrm{~A}}$ \\
3 & $9 *$ & 4 & $7^{\mathrm{D}}$ \\
4 & $19^{*}$ & $5^{*}$ & $5^{*}$ \\
5 & $15^{*}$ & 8 & $19^{* \mathrm{~A}}$ \\
6 & $13^{*}$ & $9 *$ & $3^{*}$ \\
7 & $1^{*}$ & 10 & $10^{\mathrm{D}}$ \\
8 & $3^{*}$ & $11^{*}$ & $9^{*}$ \\
9 & $5^{*}$ & $13^{*}$ & $13^{*}$ \\
10 & $22^{*}$ & 16 & $17^{* \mathrm{~A}}$ \\
\hline
\end{tabular}

The letters A and D in the "Final result" columns indicate which group originally proposed the measure (indicated by the number). Item numbers without letters correspond to measures that were common to the future (A)- and present (D)-generation groups
Table 4 Ranking before and after negotiation and consensus building between Group B (imaginary future generation) and Group C (present generation)

\begin{tabular}{lccc}
\hline Ranking & Group B & Group C & Final results \\
\hline 1 & $11^{*}$ & 11 & $9^{*}$ \\
2 & 16 & 7 & $12^{\mathrm{B}}$ \\
3 & 12 & $9^{*}$ & 7 \\
4 & $13^{*}$ & $13^{*}$ & $13^{*}$ \\
5 & 10 & $3^{*}$ & $3^{*}$ \\
6 & 7 & 23 & 23 \\
7 & $22^{*}$ & $19^{*}$ & $19^{* \mathrm{C}}$ \\
8 & 23 & 14 & $15^{* \mathrm{C}}$ \\
9 & $3^{*}$ & $1^{*}$ & $14^{\mathrm{C}}$ \\
10 & $9^{*}$ & $15^{*}$ & $1^{* \mathrm{C}}$ \\
\hline
\end{tabular}

The letters B and C in the "Final result" columns indicate which group originally proposed the measure (indicated by the number). Item numbers without letters correspond to measures that were common to the future (B)- and present (C)-generation groups

there was a marked conflict in relation to this proposal during the subsequent consensus-building session between Groups A and D, based on the sense that future generations would be strongly opposed to the proposition because it would impose a severe financial burden on them. However, Group A finally accepted the idea after considering that the idea could be modified by measures favored by future generation, and on the condition that it would be implemented under certain restrictions.

The above example partially demonstrates how negotiations proceeded in the intergenerational consensus-building process. In particular, this process actually demonstrates the intergenerational conflicts between future- and presentgeneration groups at the beginning of the session, as well as the process of reaching a mutual understanding between both groups at the end of the negotiations. Furthermore, the two group pairs, A-D and B-D, employed different strategies during their consensus building processes. Specifically, Groups A and D arrived at a final proposal by a process of repeated demands and compromises. In contrast, groups $\mathrm{B}$ and $\mathrm{C}$ started the process of selecting their final 10 policies by agreeing, without any conflict, to accept their commonly selected policies as the foundation of their final proposal. Then, they engaged in a process of negotiation to decide on the remaining policies to include.

If we look at the final proposal of 10 policies (Tables 2, 3 ), we find that 7 out of 10 in the case of pair group A-D and 6 out of 10 in the case of pair group B-C were proposed only by the imaginary future-generation groups in the second and third workshops (i.e., vision formulation workshops). We can interpret this to mean that, through a process of consensus building of future design, local residents can successfully formulate visions and policy proposals that 
substantially reflect the viewpoint of future generations. These results would have been difficult to achieve with a conventional method of vision design based on the viewpoint of present generations, as demonstrated by the fact that Groups $\mathrm{C}$ and $\mathrm{D}$ never came up with the ideas proposed by Groups A and B but were willing to substantially incorporate such ideas in their finalized proposal after the consensusbuilding processes.

\section{Characteristics of deliberation by group}

In this subsection, we summarize the characteristics of discussion, thinking pattern and judgment used by the presentand imaginary future-generation groups, as observed from the workshop series, based on the analyses conducted using all the recorded texts and graphics from the workshops. Overall, the present generation regarded the future as an extension of the present time, so they created visions that resolved present challenges within existing institutions and constraints. On the other hand, the future-generation groups were more creative and worked to depict the future from the values and lifestyles they envisioned for the year 2060, and tended to give priority to the resolution of problems that were the most complicated and time-consuming.

The main points of those observed characteristics are summarized in Table 5. Referring to that table, the following briefly explains the characteristics of future- and present-generation groups with examples of actual participant statements, particularly those that demonstrated notable differences between the future- and present-generation groups:

(1) Features of deliberation by future-generation groups

(a) Clear elaborations of the values and lifestyles of people in 2060

Discussion tended to start by considering the values and lifestyles of the people in 2060. It appears that the ultimate goals associated with the visioning and measures proposed by future-generation groups were to ensure value fulfillment and the quality of life for the town residents of 2060 . This point was illustrated by the fact that many keywords associated with values and concepts, such as creating a healthy town and maintaining the landscape of the countryside, were explicitly addressed especially at the beginning of the deliberation.

(b) Clear attention to how to best make use of local resources

Significant amounts of time were spent on addressing how to utilize local resources such as environment, culture, and history of Yahaba Town. One of the most prominent examples of this was a proposal for a new transportation system using the concept from the novel 'Night on the Galactic Railroad' by Miyazawa Kenji and the relevant Nansho Mountain, as a local resource.

(c) Proposing measures as parts of integrated stories with holistic viewpoints

Proposed visions and measures appeared to be woven into integrated stories, not simply as individual and segregated measures. For example, one idea proposed by the groups was to build a monorail line themed on the 'Night on the Galactic Railroad' novel by Miyazawa Kenji. Simultaneously, energy self-sufficiency was highlighted by a proposal that called for energy production at each station of the monorail. Here, the concept of creating monorail transportation built around the theme of a famous novel, the town's transportation policy, and the required energy policy were integrated into a single story.

(d) Institutions addressed as changeable variables rather than fixed realities

The future-generation groups tended to consider institutions and governance to be necessary for realizing their goals, and therefore changeable depending on the envisioned futures. For instance, future-generation Group A proposed establishing a stock company that would run the new transportation system instead of

Table 5 Features of deliberation by future- and present-generation groups

\begin{tabular}{|c|c|}
\hline Imaginary future-generation groups & Present-generation groups \\
\hline $\begin{array}{l}\text { Clear elaborations on the values and lifestyles of people in } 2060 \\
\text { Clear attention to how to best make use of local resources }\end{array}$ & $\begin{array}{l}\text { Strong concerns about dealing with unmet needs and visible problems } \\
\text { of today, along with ways to improve the lives of present-day residents }\end{array}$ \\
\hline $\begin{array}{l}\text { Proposing measures as parts of integrated stories with holistic view- } \\
\text { points }\end{array}$ & $\begin{array}{l}\text { Incremental and linear thoughts to improve physical facilities and exist- } \\
\text { ing institutions of the present society }\end{array}$ \\
\hline $\begin{array}{l}\text { Institutions addressed as changeable variables rather than fixed reali- } \\
\text { ties }\end{array}$ & $\begin{array}{l}\text { Strong concerns about lessening the burdens of the younger members of } \\
\text { the present society }\end{array}$ \\
\hline $\begin{array}{l}\text { High sensitivity to technological changes and future innovations } \\
\text { High sensitivity to future societal and physical changes }\end{array}$ & $\begin{array}{l}\text { High priority given to measures that would have immediate effects to } \\
\text { increase the town population }\end{array}$ \\
\hline $\begin{array}{l}\text { Explicit perception that proposed visions and measures should also } \\
\text { address the visible challenges of today }\end{array}$ & $\begin{array}{l}\text { Tendency to cite relevant and similar examples regarding projects } \\
\text { conducted elsewhere }\end{array}$ \\
\hline Attention to complicated and time-consuming challenges & Institutions and governance perceived as fixed conditions \\
\hline
\end{tabular}


the public sector entity that runs the currently existing town transportation system.

(e) High sensitivity to technological changes and future innovations

When addressing future visions, the future-generation groups demonstrated a high sensitivity to technological innovations and developments aimed at the future time horizon. One prominent example was that they hypothesized that "Given that society in 2060 will likely be highly mechanized, robotized, and technologically advanced, people will not need to move to big towns such as Tokyo to work or live. Hence, people will reside or come to Yahaba Town, as long as they sympathize with the values and lifestyles of the town."

(f) High sensitivity to future societal and physical changes

As they looked towards the time horizon of 2060, future-generation groups appeared to be very sensitive to possible and plausible changes in socio-economic and physical conditions. One example used to explain this is that Group A proposed an air traffic control system based on the idea that, with further urbanization, land in Yahaba Town in 2060 would become densely built up, making it necessary to consider how to best utilize the air above it.

(g) Explicit perception that proposed visions and measures should also address the visible challenges of today

While the future-generation groups proposed many innovative ideas with regards to visions and policy measures, they simultaneously appeared to be very aware of today's visible challenges, thus raising the possibility of win-win scenarios. One prominent example is the opinion raised by future generation group members that the proposed monorail transportation system would also create opportunities to resolve challenges faced by the present "Sawayaka" public bus system, such as low resident utilization and inconveniences related to low service frequency.

(h) Attention to complicated and time-consuming challenges

Future-generation groups appeared to pay special attention to complicated and time-consuming issues rather than focus on measures that could be implemented easily. In many cases, they commented: "Priority should be placed on the items needed to deal with complex and time-consuming issues at an earlier stage." They also tended to disregard measures that would postpone fundamental challenges.

(2) Features of deliberation by present-generation groups

(a) Strong concerns about dealing with unmet needs and visible problems of today, along with ways to improve the lives of present-day residents

The primary focus of visioning discussions by present-generation groups was on how to cope with the unmet needs of present society, concerns that have already surfaced, and ways to improve such problems. This was clearly reflected by such proposed measures as resolving the obvious area-related disparities in the quality of elementary schools and inviting enterprises to expand employment opportunities, which might result in an immediate increase in the town population.

(b) Incremental and linear thoughts to improve physical facilities and existing institutions of the present society

Rather than proposing new physical facilities and social systems to support their envisioned future, present-generation groups tended to focus on ways to improve the existing ones. This demonstrates rather "linear" ways of thinking in contrast with the innovative approach shown by future-generation groups, as discussed earlier. This point was illustrated by such proposed measures as 'Increasing residents' awareness of the existing 'Sawayaka' public transportation bus to resolve the low utilization rate".

(c) Strong concerns about lessening the burdens of the younger members of present society

Present-generation groups supported policy measures that might lessen the burdens on the present generation. For instance, The present-generation groups proposed: "It would be important to implement free or low-cost medical care for the children of the present generation" Notably, the measure (No. 7 in Table 1) was strongly opposed by the future-generation-group participants in the initial stage of consensus building between Groups A and D based on the assumption that future generations would eventually bear the resulting financial burden because the free medical care would be paid for with taxpayer money.

(d) High priority given to measures that would have immediate effects to increase the town population

Visions and policy measures that would contribute immediately towards countering population decline, demographic aging, and the declining birth rate were strongly favored by present-generation groups. Proposed policy measures such as offering public sector matchmaking services for those seeking marriage (No. 8 in Table 1) clearly provide the examples to illustrate this point.

(e) Tendency to cite relevant and similar examples regarding projects conducted elsewhere

When proposing visions and ideas, the present-generation groups tended to cite other examples or cases that have been implemented by other towns or countries. This tendency points to a psychological mindset of present-generation participants that aims at ensuring the ideas and policies proposed would be solidly workable. 
(f) Institutions and governance perceived as fixed conditions

As opposed to the case of future-generation group, the present-generation groups tended to consider social systems and institutions that exist today as given. For instance, they proposed ideas such as launching a child care center by assuming that the new center would be run by public sector (i.e., Yahaba Town), as opposed to the case of future-generation groups as was explained earlier.

\section{Discussion}

Summarizing "Judgement trends and priorities by group" and "Characteristics of deliberation by group" sections, we find that the implementation of future design debates in Yahaba Town led to the following valuable suggestions: (1) the thinking patterns of current and imaginary future generations are different as summarized in "Characteristics of deliberation by group" section; (2) so-called intergeneration conflicts of interest are recreated because the criteria for ranking and selecting policies differ significantly according to the viewpoint of each generation; (3) the process of future design debates makes present generations more aware of the viewpoint of an imaginary future generation, thereby creating enhanced opportunities for mutual understanding with both generations; and (4) vision and policy proposals that might not have emerged if only the viewpoint of present generations had been considered were incorporated, to a large degree, into the policymaking process. These points highlight the fact that the processes used when envisioning futures from the viewpoints of present and future citizens are fundamentally different. This, in turn, makes our approach, which is based on engaging actors to represent the interests of future generations in present-day political decision-making processes, very significant.

Next, we will discuss the characteristics of the future design method that we introduced in this paper in comparison to existing methods, such as backcasting. The first point to consider is the clearly observed differences in normativity and values in terms of a sustainable society that exist between present- and future-generation groups, as outlined in "Judgement trends and priorities by group" and "Characteristics of deliberation by group" sections. Obviously, such normative aspects in relation to a desirable and sustainable Yahaba Town constitute the core of visions for 2060 and the relevant policy measures proposed by both groups.

By putting themselves into the shoes of future generations, the participants tasked with representing future generations appear to have prioritized values in a different manner than those tasked with representing the present generation.
Although efforts aimed at sharing normative scenarios while considering desirable future states based on problem identification have been commonly integrated into other methods such as backcasting (Wiek and Iwaniec 2014; Eames and Egmose 2011; Sandström et al. 2016; Quist and Vergragt 2006), our study clearly demonstrated that incorporating the perspectives of imaginary future-generation groups could lead to the creation of different normative values, eventually resulting in differences in ultimate visioning and decision making.

In relation to this point, we argue that the creativity displayed towards an envisioned future and the relevant measures proposed to achieve it was much higher in the futuregeneration group than in the present-generation group, as was shown earlier. We believe this fact relates to the differences in the normative values of a sustainable society as seen by the present and future generations, which was the starting point of the discussion. In the future, detailed analyses must be conducted to determine the actual mechanisms behind such differences, particularly in terms of ways of thinking and the judgments made, possibly by introducing such disciplines as neuroscience.

The second point is the differences in the incentives proposed as ways to transform attitudes towards the achievement of set visions. One prominent example used to discuss this point is elaborated in "Judgement trends and priorities by group" section, where the present-generation groups valued "providing free medical and daycare for children" since immediate effects could be anticipated. This policy was strongly supported by that group as one of the most important measures for adoption during the consensusbuilding session. However, it was strongly opposed by the future-generation groups based on the proposition that such measures would eventually impose a severe financial burden on them. Clearly, the decision-making incentives envisioned by the imaginary future-generation groups were influenced primarily by the well-being of the future generation.

In contrast, the aspects of such incentives in relation to societal transitions and associated decision making have not clearly been addressed in the existing methods for envisioning the future (Ligtvoet et al. 2016; Oliver 2008; Kuzmanovic and Gaffney 2017; Eames and Egmose 2011). We also argue that "futurability", which is the core concept of future design, as defined in "Creating imaginary future generations: incorporating the viewpoints of future generations into the present" section, could explain the differences in incentives and judgments seen in the future-generation groups.

In addition to these points above, the practices of future design can be expected to have more implications than the social learning type of effects associated with backcasting and other relevant methods (Robinson 2003; Quist and 
Vergragt 2006; Kuzmanovic and Gaffney 2017; Ligtvoet et al. 2016). Researchers conducted interviews with imaginary future generation participants to examine their way of thinking in greater detail and found that some of the prominent characteristics associated with those who represented imaginary future generations were as follows (Nakagawa et al. 2017).

First, the participants who had been acting as imaginary future persons showed no conflicts of interest between the viewpoints of the current generation and those of their imaginary future generation, since they had a comprehensive overview of both perspectives. Notably, the effects of having such comprehensive viewpoints tended to last for some time, which indicates their robustness.

The second point is that those who represented future generations experienced feelings of joy and intellectual enlightenment because they had come to view things via a way of thinking that had not existed within themselves previously. While further studies will be needed to explain the actual mechanisms of these points in greater detail, it can be said that the practice of future design has significant effects and is not simply social learning, as indicated above, which makes the approach unique. Since we hypothesized that this also has to do with futurability, the relationship between these points will be further explored in future studies.

Meanwhile, although our future design method and other existing methods such as backcasting are different in several ways, as discussed above, it is imperative that we explore the possibility of using them in a complementary manner to take the fullest advantage of their individual merits and characteristics. Such method combinations have the potential to enhance the ability to cope with various future problems we face. This aspect will be one of the themes of our future research.

In addition to the points above, we consider it necessary to examine the following essential points in our future studies. The first point to be more closely analyzed is the conditions for effectively creating imaginary future generations. In the present case study, we set specific conditions in the process of creating imaginary future generations and employed unified wording and examples (global warming). Verification of these instruction methods through accumulation of further case studies will be necessary to ensure their effectiveness and objectivity.

In relation to the first point, the second point to be studied comprises methods for providing information in future design debates. To accomplish this, it is essential to avoid information biases while expanding our imagination about the future. This case study was intentionally restricted to a limited amount of information and was centered on facts such as socioeconomic statistical data related to Yahaba Town. Since the way that data are provided also influences the judgment of participants, further and more careful examination is required. From that viewpoint, it will be necessary to study what kind of information should be provided and in what ways, again by accumulating case studies under different conditions and contexts.

The third point is the need to develop criteria and indicators for analyzing and evaluating ways of thinking that consider the needs of future generations. From this workshop series, we discovered that the thinking patterns and criteria for policy ranking used by imaginary future- and presentgeneration-group participants are quite different. However, since any thinking about future generations depends on the context of the issues being dealt with, further research is also needed in this area. In this regard, we intend to carry out detailed analysis on how participants of imaginary futuregeneration groups framed discussion topics in deliberation and negotiating processes by interviewing.

Finally, it will also be important to deepen knowledge about how to mobilize and select participants for a future design workshop. From the viewpoint of implementing the future design method in real policy making, either at a local or governmental level, we need more in-depth understanding about how best to select people and what kinds of rights and responsibilities should be given to such participants (both present and future generations). This will be an essential point to delve into in the future.

Yahaba Town is the first local municipality experimenting with participation-style future design. Therefore, another future issue is the need to analyze the conditions under which participation-style future design is socially implemented by accumulating case studies and examining the effectiveness and significance of imaginary future generations under a variety of conditions.

\section{Conclusions}

To build a truly sustainable society, viewing the future solely from the viewpoint of the present generation is very limiting. Accordingly, it is necessary to develop and implement practical new methods of overcoming intergeneration conflicts of interest by clearly incorporating the viewpoints and interests of future generations into present decision-making processes. The future design process that we have proposed in this study provides a novel approach to this challenge that creates imaginary stakeholders of future generations that participate in negotiation and decision making with the present generation. It would be essential to consider supplementary systems and methods, such as our approach, to activate "futurability" of people in decision making to overcome possible intergenerational conflicts and to realize a sustainable society.

Through a case study, we showed the existence of a stark contrast in the characteristics of deliberation by the 
imaginary future- and present-generation groups. Furthermore, we demonstrated that the ideas proposed by imaginary future-generation groups could influence the decision making of present-generation groups, and that consensus-building processes by the paired groups led to decision-making processes that included the preferences of future generations. We found from the study that normative aspects, such as the values associated with a sustainable Yahaba Town, and the incentives related to transforming society toward the set vision were very different between present- and future-generation groups. This fact could also be explained by introducing the concept of "futurability".

We contend that creating imaginary future-generation groups in deliberation and negotiating processes has the potential to help cope with intergenerational conflicts over present-day decision making by incorporating the preference of future generations. Although the significance and effectiveness of creating imaginary future generations can be recognized by the case study in Yahaba Town, we must await the results of future studies, as addressed earlier, so that participatory future design debates can become more firmly established as a practical social technology.

Acknowledgements This study was supported by a Grant-in-Aid for Scientific Research (Research Project No. 16K12660 and 17H00980) from the Japan Society for the Promotion of Science and the program "Designing a Sustainable Society through Intergenerational Co-creation" operated by Research Institute of Science and Technology for Society of the Japan Science and Technology Agency.

\section{Compliance with ethical standards}

Conflict of interest The authors declare that they have no conflict of interest.

Open Access This article is distributed under the terms of the Creative Commons Attribution 4.0 International License (http://creativeco mmons.org/licenses/by/4.0/), which permits unrestricted use, distribution, and reproduction in any medium, provided you give appropriate credit to the original author(s) and the source, provide a link to the Creative Commons license, and indicate if changes were made.

\section{References}

Carlsson-Kanyama A, Dreborg KH, Moll HC, Padovan D (2008) Participative backcasting: a tool for involving stakeholders in local sustainability planning. Futures 40:34-46

Clark WC, Dickson NM (2003) Sustainability science: the emerging research program. Proc Natl Acad Sci USA 100(14):8059-8061

Demeny P (1986) Pronatalist polices in low-fertility countries: patterns, performance, and prospects. Popul Dev Rev 12(supplement):335-358

Eames M, Egmose J (2011) Community foresight for urban sustainability: insights from the Citizens Science for Sustainability (SuScit) project. Technol Forecast Soc Chang 78(5):769-784
Eickhoff P, Geffer SG (2009) Power of imagination studio: a further development of the futureworkshop concept. In: Holman P, Devane T, Cady S (eds) The change handbook: the definitive resource on today's best methods for engaging whole systems. Berrett-Koehler Publishers, San Francisco, pp 27-35

Fehr-Duda H, Fehr E (2016) Sustainability: game human nature. Nature 530:413-415

Fischbacher U, Gächter S, Fehr E (2001) Are people conditionally cooperative? Evidence from a public goods experiment. Econ Lett 71:397-404

Hara K (2016) Participatory future design in pursuit of sustainability. Des Eng 51(5):297-302 (In Japanese)

Hara K, Saijo T (2017) Future design: evidence and insights from participatory deliberations. J Jpn Soc Water Environ 40(4):112116 (In Japanese)

Hara K, Saijo T, Kurimoto S, Kishita Y, Uwasu M, Fuchigami Y (2015) Will people's perceptions and judgements change in view of future generations? Evidence from a questionnaire survey. In: Proceedings of EcoDesign 2015 international symposium, pp 105-107

Hara K, Kumazawa T, Kimura M, Tsuda K (2016a) Participatory approach in vision setting: emerging initiatives in local municipalities in Japan. Sustain Sci 11(3):493-503

Hara K, Kumazawa T, Kimura M, Tsuda K (2016b) Participatory approach in vision setting: emerging initiatives in local municipalities in Japan. Sustain Sci 11(3):493-503

Iacovidou E, Wehrmeyer W (2014) Making sense of the future: visions and transition pathways of laypeople and professionals from six EU countries. Global Bioeth 25(4):211-225

Innes J, Booher D (2003) Collaborative policy making: governance through dialogue. In: Hajer M, Wagenaar H (eds) Deliberative policy analysis: understanding governance in the network society. Cambridge University Press, New York, pp 33-59

Kamijo Y, Hizen Y, Saijo T (2015) Hearing the voice of future generations: a laboratory experiment of Demeny voting. Kochi University of Technology, Social Design Engineering Series, SDES-2015-8. http://www.souken.kochi-tech.ac.jp/seido/wp/ SDES-2015-8.pdf. Accessed 23 Sept 2017

Kamijo Y, Komiya A, Mifune N, Saijo T (2017) Negotiating with the future: incorporating imaginary future generations into negotiations. Sustain Sci 12(3):409-420

Kates RW, Clark WC, Corell R, Hall JM, Jaeger CC et al (2001) Sustainability science. Science 292(5517):641-642

Kishita Y, Hara K, Uwasu M, Umeda Y (2016) Research needs and challenges faced in supporting scenario design in sustainability science: a literature review. Sustain Sci 11(2):331-347

Komiyama H, Takeuchi K (2006) Sustainability science: building a new discipline. Sustain Sci 1(1):1-6

Kumazawa T, Kozaki K, Matsui T, Saito O, Ohta M, Hara K, Uwasu M, Kimura M, Mizoguchi R (2014) Initial design process of the sustainability science ontology for supporting co-deliberation. Sustain Sci 9(2):173-192

Kuzmanovic M, Gaffney N (2017) Enacting futures in postnormal times. Futures 86:107-117

Ligtvoet A, Cuppen E, Ruggero OD, Hemmes K, Pesch U, Quist J, Mehos D (2016) New future perspectives through constructive conflict: exploring the future of gas in the Netherlands. Futures 78-79:19-33

Nakagawa Y, Hara K, Saijo T (2017) Becoming sympathetic to the needs of future generations: a phenomenological study of participation in future design workshops, Kochi University of Technology, Social Design Engineering Series, SDES-2017-4. http:// www.souken.kochi-tech.ac.jp/seido/wp/SDES-2017-4.pdf. Accessed 23 Sept 2017

Nakagawa Y, Kotani K, Matsumoto M, Saijo T (2019) Intergenerational retrospective viewpoints and individual policy preferences for 
future: a deliberative experiment for forest management. Futures 105:40-53

Oliver WM (2008) Mental time travel: a practical business and personal research tool for looking ahead. Futures 40:17-24

Quist J, Vergragt P (2006) Past and future of backcasting: the shift to stakeholder participation and a proposal for a methodological framework. Futures 38:1027-1045

Robinson JB (2003) Future subjunctive: backcasting as social learning. Futures 35:839-856

Saijo T (2017) Future design. Econ Rev 68(1):33-45 (In Japanese)

Saijo T (ed) (2018) Future design: incorporating preferences of future generations for sustainability. Springer, Berlin

Saijo T (2019) Future design. In: Moulin H (ed) Future of economic design. Springer, Berlin

Sandström C, Carlsson-Kanyama A, Lindahl KB, Sonnek KM, Mossing A, Nordin A, Nordström E-M, Räty R (2016) Understanding consistencies and gaps between desired forest futures: an analysis of visions from stakeholder groups in Sweden. Ambio 45:100-108

Sapolsky RM (2012) Super humanity. Sci Am 307(3):40-43
Schneider F, Rist S (2014) Envisioning sustainable water futures in a transdisciplinary learning process: combining normative, explorative, and participatory scenario approaches. Sustain Sci 9:463-481

Shahrier S, Kotani K, Saijo T (2017) Intergenerational sustainability dilemma and the degree of capitalism in societies: a field experiment. Sustain Sci 12(6):957-967

Sherstyuk K, Tarui N, Ravago MV, Saijo T (2016) Intergenerational games with dynamic externalities and climate change experiments. J Assoc Environ Res Econ 3(2):247-281

Wiek A, Iwaniec D (2014) Quality criteria for visions and visioning in sustainability science. Sustain Sci 9:497-512

World Commission on Environment and Development (1987) Our common future. Oxford University Press, New York

Publisher's Note Springer Nature remains neutral with regard to jurisdictional claims in published maps and institutional affiliations. 